\title{
OS LIMITES DA AUTONOMIA EXISTENCIAL E OS DEVERES JURÍDICOS FUNDAMENTAIS DE PRESERVAÇÃO DA VIDA DE PESSOAS INCONSCIENTES
}

\section{THE LIMITS OF EXISTENTIAL AUTONOMY AND THE FUNDAMENTAL LAW DUTIES OF PRESERVING INCONSCIOUS PEOPLE LIVES}

\author{
Ana Stela Vieira Mendes Câmara ${ }^{1}$ \\ Gabrielle Bezerra Sales ${ }^{2}$
}

\section{RESUMO}

Diante das incertezas fáticas, conceituais e científicas em torno da terminalidade da vida, e admitindo-se a busca pelo ideário de uma morte digna, natural e adequada, sem antecipações ou prolongamentos indevidos, o presente trabalho tem por escopo investigar a razoabilidade dos parâmetros que estabelecem limitações à autonomia existencial, em face da preservação da vida de pessoas inconscientes. Identifica-se, com base no componente heterônomo da dignidade humana, a existência de um feixe de deveres jurídicos fundamentais de proteção desses indivíduos cuja titularidade cabe à família e ao Estado. Trata-se de pesquisa qualitativa, interdisciplinar, bibliográfica e documental, em que se utilizou abordagem hipotética-dedutiva.

Palavras-chave: Ortotanásia; Autonomia existencial; Deveres fundamentais; Pessoas inconscientes.

\begin{abstract}
In the face of factual, conceptual and scientific uncertainties surrounding the finitude of life, and assuming the search for the ideal of a dignified, natural and proper death without prepayments or undue extensions, this research has the scope to investigate the reasonableness of the parameters that establish limitations on existential autonomy, due to the preservation of life of unconscious people. Identifies, based on heteronomous component of human dignity, the existence of a bundle of basic legal duties of protection of these individuals whose ownership rests with the family and the state. The methodology is qualitative, interdisciplinary bibliographic and documentary, in which it is used hypothetical-deductive approach.
\end{abstract}

Keywords: Orthothanasia; Existential autonomy; Fundamental duties; Unconscious people.

\footnotetext{
${ }^{1}$ Graduada, Mestre e Doutora em Direito pela Universidade Federal do Ceará, advogada, professora e Coordenadora Geral de Pesquisa e Extensão no Centro Universitário Christus. Ceará (Brasil). E-mail: emaildastela@ gmail.com ${ }^{2}$ Graduada e Mestre em Direito pela UFC- Universidade Federal do Ceará, Doutora em Direito pela Universidade de Augsburg- Alemanha, advogada, professora e coordenadora geral do Curso de Direito do Centro Universitário Christus. Ceará (Brasil). E-mail: gabriellelinhares@ hotmail.com
} 


\section{APROXIMAÇÕES}

Um dos maiores desafios da Humanidade é a percepção da sua própria finitude. A respeito da vida e da morte fazem-se anedotas ${ }^{3}$, escrevem-se livros (SARAMAGO, 2004), compõem-se músicas, ou seja, são encetadas narrativas que traduzam e expressem essa complementariedade radical. Apesar das evidências da suposta naturalidade desse assunto, não se pode afirmar, com isso, que seja menos delicado, pois remete, como dizem os cantores, a “encontros e despedidas" (NASCIMENTO; BRANDT, 1999), ou os poetas, à incerteza, à angústia de quem vive (MORAES, 1957).

Na contramão do desenvolvimento de novos medicamentos, do avanço da biotecnologia e do consequente aumento das possibilidades de prolongamento artificial da vida, a morte passa a ser cada vez mais asséptica, desumanizada e menos aceita como um fenômeno natural. De certo modo, gradativamente a morte se afirma como um dos maiores tabus da civilização ocidental.

Com efeito, restam também cada vez mais tênues os limites entre a vida e a morte e acentuam-se as dificuldades de se estabelecer as fronteiras entre a morte antecipada, a morte natural - tempestiva, e a morte com sofrimento prolongado, o que finda por gerar em pacientes terminais ou em portadores de enfermidades degenerativas e em seus familiares os questionamentos sobre a equação entre a vida, a morte, a liberdade e a dignidade. Relevante é a indagação sobre os limites do consentimento e a autonomia do sujeito ou, na falta deste, o de seus responsáveis legais para determinar o momento do óbito, segundo o artigo 22 do Código de Ética Médica.

Nesse contexto, partindo da premissa do direito fundamental à vida e de algumas faces da autonomia da vontade, o presente estudo tem por objetivo investigar os contornos da proteção jurídica que deve ser conferida à vida de pacientes inconscientes, seja por estado vegetativo persistente ${ }^{4}$, seja por avanço de enfermidade degenerativa, em caso de solicitação por seus responsáveis de medidas que tenham a finalidade de provocar a morte prematura do paciente (eutanásia ativa e passiva).

\footnotetext{
${ }^{3} \mathrm{O}$ sujeito está à procura de um endereço que tem como ponto de referência o cemitério. Perdido, indaga a um dos moradores dos arredores: "como faço para chegar ao cemitério", ao que lhe responde, impassível: "só morrendo, meu senhor!!!"

${ }^{4}$ Não se pode deixar de observar a conotação pejorativa deste termo, que ofende a condição de pessoa. O termo mais apropriado, coma vigil, não será aqui utilizado, haja vista a confusão terminológica existente e que pode ocasionar.
} 
Embora a eutanásia seja uma prática proibida no Brasil, o interesse por essa temática se justifica, dentre outros elementos já mencionados, a partir da constatação de que, sob a crescente influência do individualismo pós-moderno, o Brasil passa por um momento de discussão e de reconhecimento judicial de uma série de direitos relacionados ao exercício da liberdade e da dignidade que antes eram considerados verdadeiros tabus ${ }^{5}$, como a permissão do abortamento de fetos anencéfalos, parecendo seguir uma tendência de liberalização de certas condutas, a exemplo do que tem acontecido em países como Holanda e Bélgica, entre outros (PONTES, 2012).

Realidade esta que acaba por implicar na discussão sobre os direitos dos pacientes em estado vegetativo, por razões análogas, a partir de seu quadro de irreversibilidade, mas, sobretudo, porque "constituem uma população especialmente vulnerável e de baixa visibilidade" (MARTEL; BARROSO, [s.d.], p. 12). Inegável se tratar de temática atual e inquietante. Daí, a relevância de uma investigação minuciosa desse recorte da realidade contemporânea. Para tanto, utilizou-se uma abordagem qualitativa, transdisciplinar, com pesquisa em acervo bibliográfico, documental e digital.

\section{SOBRE O MORRER: DELIMITAÇÕES CONCEITUAIS E PRINCIPAIS CLASSIFICAÇÕES}

Embora marcada simbolicamente por sinais biológicos, como o último suspiro ou o parar do coração, a morte, fim de quem vive, não consiste em um único ato, mas sim em um processo lento ou rápido de perda de funções vitais ${ }^{67}$, modernamente laicizado e encarado como técnico, no qual se relacionam o paciente, seus achegados e os médicos (BAIGES, 2002).

De acordo com Baiges (2002, p. 51), faz parte desse processo a tomada de uma série de decisões, como "a de tratar o de no tratar, de prosseguir o de interrumpir un tratamento etc", que deverão ser regulamentadas pelo Direito.

O tratamento jurídico destinado a essas situações leva em consideração alguns elementos essenciais, por vezes, conflitantes: a regra geral de proteção à vida, a autonomia existencial, a

\footnotetext{
5 Sobre o tema vide Res CFM 1803/2006; Res CFM 1931/2009; Res CFM 1995/2012. In: <http://www.portalmedico.org.br/resolucoes/cfm>. Acesso em: 10 fev. 2016.

${ }^{6} \mathrm{O}$ momento preciso da morte divide cientistas, que chegam a estabelecer a existência de vários conceitos distintos para a morte: morte clínica, morte biológica, morte óbvia, morte encefálica, morte cerebral, morte jurídica e morte psíquica (SIQUEIRA-BATISTA; SCHRAMM, 2004).

${ }^{7}$ Para os efeitos deste trabalho, o qual, pelo seu formato, não comporta esta discussão, considerar-se-á como válido e legítimo o critério que veio a ser consensuado pela legislação brasileira, qual seja, o da morte encefálica, conforme o art. $3^{\circ}$, caput, da Lei 9.434 , de 4 de fevereiro de 1997, que dispõe sobre a remoção de órgãos, tecidos e partes do corpo humano para fins de transplante e tratamento e dá outras providências.
} 
dignidade da pessoa humana (NOVAIS, 2015), o dever de cuidado da família e dos profissionais da saúde para com o paciente e a noção de morte digna, variando de país para país as conclusões a que se chega, no que concerne à permissividade ou à proibição de determinadas condutas: a eutanásia, a distanásia e a ortotanásia ${ }^{8}$.

A eutanásia pode ser definida como a conduta ou a omissão que ocasione "antecipação da morte de paciente incurável, geralmente terminal, e em grande sofrimento, movido por compaixão para com ele"9 10 . Já distanásia é "a morte lenta, e sofrida, prolongada, distanciada pelos recursos médicos, à revelia do conforto ou da dignidade do indivíduo que morre" (VILLAS-BÔAS, 2008, p. 67). Decorre do encarniçamento ou da obstinação terapêutica e da aplicação de tratamento fútil, termos que designam os comportamentos excessivos e inúteis para evitar o inexorável fim da vida que se aproxima. Reflete a falta de aceitação da morte como um processo natural por parte de médicos e ou dos familiares.

A ortotanásia, por sua vez, é a ocorrência do processo de morte em seu tempo devido, de maneira natural, sem antecipação ou prolongamento cruel. É um ideal a ser buscado pela comunidade médica caso a caso e está associado, segundo Martel, a uma aceitação do curso da vida, à estratégia de humanização da morte (MARTEL, 2010). Enseja, desse modo, a manutenção de cuidados básicos para proporcionar ao paciente, dentro das especificidades de

\footnotetext{
${ }^{8}$ Naturalmente, a primeira providência para avaliar tais procedimentos perpassa pela distinção destes termos. Entretanto, é preciso advertir sobre a existência de significativas dissonâncias doutrinárias, que repercutirão na consideração da razoabilidade de determinadas práticas ou não. Em consulta ao estado-da-arte do tema no Brasil, esclarece-se a opção pela classificação adotada por Maria Elisa Villas-Bôas, ao passo que também se trará, para efeito de conhecimento e exame da proposta ora apresentada, aquela adotada por Letícia de Campos Velho Martel. ${ }^{9}$ Boa parte da doutrina, a exemplo de Silva (2011), afirma que, para que haja a configuração da eutanásia, é necessário que a conduta de por termo à vida de outrem seja intencional. Villas-Bôas (2008), ao contrário, admite a existência da eutanásia direta (dolosa) e indireta ou de duplo efeito, nos casos em que a administração do remédio paliativo, em razão de seus efeitos colaterais, venha a antecipar o resultado morte, o qual, não era tido como provável, embora fosse possível (culpa consciente), ou, que mesmo não sendo desejado, arriscou-se produzir (dolo eventual). As consequências práticas desta distinção parecem praticamente inexistentes, haja vista a eutanásia de duplo efeito ou indireta ser descriminalizada e aceita até pela Igreja Católica. Segundo a autora, "sabendo-se que toda medicação traz em si algum efeito colateral, não parece devido impor a dor sem controle ao ser humano no final da vida, quando há medicação capaz de aliviá-lo, ainda que aumentando o risco de apressar o desfecho letal pela gradativa intoxicação".

${ }_{10}$ Alguns autores defendem que somente a eutanásia ativa, ou seja, aquela provocada por uma ação médica comissiva, estando as ações omissivas [aqui denominadas eutanásia passiva] inseridas em outras categorias, do gênero Limitação Consentida de Tratamento, como: Retirada de suporte vital (RSV), Não-oferta de suporte vital (NSV). De acordo com as palavras da autora, "Vê-se, portanto, que o rearranjo conceitual apresentado atinge a antiga distinção entre as formas ativa e passiva da eutanásia, que passaram a receber denominações distintas. O termo eutanásia aplica-se somente àquela que era conhecida como forma ativa. Além disso, a conduta que caracterizava a eutanásia passiva deixou de ser visualizada como antiética, para constituir-se em manifestação de liberdade do paciente e no dever de respeito por parte da equipe de saúde". (MARTEL, 2010, p. 340). Entretanto, a questão não é tão simples, pois nas condutas descritas como eutanásia passiva haverá sempre a clara intenção de matar e não de evitar sofrimento que leve irremediavelmente à morte (VILLAS-BÔAS, 2008).
} 
sua condição, o maior bem-estar, algum conforto e a serenidade possível para se preparar para o momento da morte, cuja inevitabilidade foi peremptoriamente diagnosticada.

Além dos cuidados paliativos, expressos em ações, a ortotanásia também pode implicar em omissão ou em suspensão do suporte vital, entendidos, em sentido estrito, como “o desligamento ou a não introdução de aparelhos de ventilação mecânica e à omissão ou à interrupção do uso de drogas que estimulam o funcionamento cardíaco" (VILLAS-BÔAS, 2008, p. 69), sendo possível inserir aqui a ordem de não reanimar, em determinados casos.

Contudo, de acordo com Villas-Boas (2008, p. 70), não se pode admitir a retirada de higiene, alimentos e hidratação, tendo em vista que são "necessidades permanentes e inarredáveis da condição humana. Sem o seu provimento, o resultado morte é certeza e consequência inevitável".

Importa ainda lembrar que, do ponto de vista clínico, na prática, poderão ser sutis as distinções entre a eutanásia passiva, a ortotanásia e, consequentemente, a própria distanásia, devendo cada caso ser objeto de criteriosa avaliação de junta médica e, em caso de dúvidas, deve-se ter por princípio de atuação a opção pela vida, sendo esta a postura considerada igualmente adequada tanto do ponto de vista da ética médica quanto do da bioética ${ }^{11}$.

\section{MORTE, AUTONOMIA, DIGNIDADE E (IN)CONSCIÊNCIA: EXISTE UM DIREITO DE MORRER?}

Muitas vezes, em nome da mesma dignidade que fundamenta o direito à vida, e da autonomia da vontade, alguns autores passaram a defender propriamente a existência de um direito de morrer, diante de situações de sofrimento intenso (ANJOS, 1998), tendo em vista as áridas limitações de integridade física, de mobilidade, de capacidade de exercício das atividades cotidianas ou, até mesmo, em razão da inconsciência, que ocasionariam uma espécie de esvaziamento, gerando uma perda no sentido da vida.

Contudo, é preciso ponderar com Martel que "não é preciso ir tão longe para humanizar a morte e o processo de morrer”(MARTEL, 2010, p. 325). Para ela, parece inadequado o reconhecimento de um direito de morrer, seja pelo ponto de vista estrutural da teorização dos

\footnotetext{
11 "Na eutanásia passiva, omitem-se ou suspendem-se arbitrariamente condutas que ainda eram indicadas e proporcionais, que poderiam beneficiar o paciente. Já as condutas médicas restritivas são lastreadas em critérios médico-científicos de indicação ou não-indicação de uma medida, conforme a sua utilidade para o paciente, optando-se conscienciosamente pela abstenção, quando já não exerce a função que deveria exercer, servindo somente para prolongar artificialmente, sem melhorar a existência terminal" (VILLAS-BÔAS, 2008, p. 63)
} 
direitos fundamentais ${ }^{12}$, ou seja, simplesmente, pelo fato da morte ser um fenômeno natural e inevitável.

De fato, o que se pondera é acerca da temporalidade da vida e das possibilidades de controle do intervalo vivido em que a racionalidade pudesse apontar para a valorização de um todo, uma vez que nem sempre pode ser mensurado por critérios de produtividade ou similares.

Ademais, isso não significa a negativa ao reconhecimento do direito a uma morte digna. Sobre isso, Baiges (2002, p. 51) entende que:

hablar de un derecho a morir con dignidade es hablar de un derecho reconocido legalmente a los individuos para que puedan tomar por sí mismos algunas de las decisiones relativas a ciertos asuntos que atañen a su propia muerte. Ese derecho se constituye así como un conjunto de facultades que garantizan un ámbito de decisión propio a los individuos en lo que se refiere a su proceso de morir, y que permite por lo tanto a éstos governar sin injerencias una parte de su muerte.

As questões atinentes ao consentimento, portanto, têm se tornado cada vez mais relevantes para o debate em torno da eutanásia, pois, de fato, é inaceitável a ausência de protagonismo nos processos decisórios que envolvem a terminalidade da vida ${ }^{13}{ }^{14}$, sob pena de ofensa à dignidade humana, em sua conjugação com a autonomia ${ }^{15}$.

Entretanto, há que se examinar com cautela dos limites dessa esfera de decisão, para que esta não venha a implicar em absoluta disponibilidade do direito à vida ${ }^{16}$. O próprio Baiges, quando expõe os axiomas do eventual conteúdo do direito de morrer com dignidade ${ }^{17}$, inclui

\footnotetext{
12 "Supondo que se reconheça um direito de morrer de estatura constitucional, haverá que se justificar por que os indivíduos não o titularizam, ou se titularizarem, porque seu exercício não será conferido a todos. Terá que se justificar porque seu suporte fático é tão restrito. [...] Se houver direito de morrer, os titulares terão que sinalizar que [...] se pretendia viver e não ser morto. [...] É um direito cuja operacionalização inverte premissas básicas das teorias dos direitos fundamentais e do Estado Constitucional de Direito"(MARTEL, 2010., p. 324).

${ }^{13}$ Segundo Diniz e Costa ([s.d.], p. 123) , "Um número crescente de pessoas, especialmente idosas, procura auxílio de médicos e enfermeiras não apenas para tratar doenças, mas para garantir que a experiência de morte seja também resultado de escolhas individuais".

${ }^{14}$ Martel e Barroso ([s.d.], p. 12) denominam de paternalismo jurídico o modelo que priva o paciente e seus familiares de realizar escolhas morais próprias.

${ }^{15}$ De acordo com as explicações de Martel e Barroso([s.d.], p. 18), a dignidade humana como autonomia assenta-se em quatro aspectos essenciais: "a) a capacidade de autodeterminação; b) as condições para o exercício da autodeterminação; c) a universalidade; d) a inerência da dignidade ao ser humano".

16 "Dispor de um direito fundamental é enfraquecer, por força do consentimento do titular, uma ou mais posições subjetivas de direito fundamental perante terceiros - que seja o Estado, quer sejam particulares -, permitindo-lhes agir de forma que não poderiam, tudo o mais sendo igual, se não houvesse o consentimento" (MARTEL, 2010, p.69).

${ }^{17}$ Seriam eles: direito a rejeitar toda decisão alheia que leve a uma morte não desejada [eutanásia "imposta"]; direito a morrer com serenidade e dignidade humana; direito a rejeitar o encarniçamento terapêutico; o direito a rejeitar qualquer tratamento médico, mesmo que isto conduza a morte; direito a manifestar vontades antecipadas sobre o processo de morrer com caráter vinculante para terceiros, direito a obter o tratamento paliativo de dor durante o processo de morrer; direito de determinar o momento da própria morte (BAIGES, 2002).
} 
alguns elementos questionáveis do ponto de vista da dignidade considerada como heteronomia ${ }^{18}$ - a qual limita a liberdade do sujeito para preservá-lo - dentre os quais se quer destacar, genericamente, no que interessa aos propósitos deste trabalho, o direito de determinar o momento da própria morte, por manifestação de vontade, em casos de pacientes inconscientes.

Insere-se ainda, para efeitos da discussão que se pretende travar, os casos em que os cuidadores responsáveis por pacientes inconscientes (termo pelo qual se designa os sujeitos em estado vegetativo persistente, portadores de doenças degenerativas graves em estágio avançado, ou qualquer outra enfermidade que os impossibilitem de, por qualquer forma de comunicação, expressar eventuais vontades) queiram suprir o seu consentimento e determinar o momento de suas mortes.

Alguns autores admitem, em diferentes perspectivas, a possibilidade de antecipação da morte em pacientes inconscientes. $\mathrm{Na}$ visão utilitarista defendida por Singer, por exemplo, aparentemente não há sequer de se falar em antecipação de morte para pessoas inconscientes, tendo em vista que a inconsciência para ele é sinônimo de morte.

É o que se infere das palavras de Silva: "Singer propõe e defende que devem ser apenas as funções cerebrais relacionadas com a consciência as únicas capazes de se apresentarem como um marcador de diferença entre a vida e a morte" [...] permitindo, dessa forma, "a consideração como morta de uma pessoa irreversivelmente desprovida de consciência" (SILVA, 2011, p. 29$30)^{19}$.

Embora o raciocínio de Singer esteja amparado por um sistema de ideias e princípios éticos coerentes entre si, é difícil aceitá-lo, em face de tantas incertezas que permeiam o próprio conhecimento e o diagnóstico de algumas situações limítrofes entre a vida e a morte, a consciência e a inconsciência, entre os estados de coma considerados reversíveis ou não, as especificidades e as formas de reagir de cada indivíduo, ou mesmo sobre exatamente o que ocorre com as pessoas que enfrentam estas situações.

A rigor, na medida em que se considera alguns relatos (FLÁVIA, 2007, online) de cuidadores de pacientes inconscientes e, muito menos, se possa desprezar as diversas

\footnotetext{
18 A dignidade como heteronomia "traduz uma visão da dignidade ligada a valores compartilhados pela comunidade, antes que a escolhas individuais. [...] Nesta acepção, a dignidade não é compreendida na perspectiva do indivíduo, mas como uma força externa a ele, tendo em conta os padrões civilizatórios vigentes e os ideais sociais do que seja uma vida boa. [...] funciona muito mais como uma constrição externa à liberdade individual do que como um meio de promovê-la [...] como freio à liberdade, no sentido de obstar escolhas que possam comprometer valores sociais ou a dignidade do próprio indivíduo cuja conduta se cerceia": ([s.d.], p. 22).

${ }^{19}$ SILVA, Mário Tavares da. op.cit., p. 29-30.
} 
manifestações de vida, torna-se inapropriado aceitar esse conceito de morte defendido por Singer.

Ronald Dworkin (apud SILVA, 2011), para quem a vida humana possui um valor intrínseco ou objetivo e, além disso, um valor individual, já que cada pessoa tem a responsabilidade em conduzir a própria vida e alcançar seus objetivos, é igualmente um dos autores fundamentais para a percepção desse panorama. Juntas, essas dimensões formam uma face da concepção de dignidade da pessoa humana e, como se vê, podem ser associadas ao que neste trabalho se vem denominando de dignidade como heteronomia e dignidade como autonomia.

Do confronto dessas duas perspectivas, tem-se que o Estado pode agir de duas maneiras: ou deixar os indivíduos decidirem por si as questões relativas às convicções morais ou determinar o modelo a ser seguido, a partir de um processo decisório que se legitima por meio do consenso.

Dessa maneira, Dworkin entende que o Estado não pode impor aos cidadãos uma maneira de morrer, pois essa conduta estaria fundada em bases paternalistas, e, da mesma maneira que julga que "a vida sem vontade de viver não parece constituir um valor digno de proteção"(apud SILVA, 2011, p. 52), entende que a eutanásia pode ser praticada, desde que seja fruto do consentimento expresso do indivíduo.

No que concerne aos pacientes inconscientes, portanto, o autor vislumbra a possibilidade legítima da eutanásia em algumas circunstâncias, embora não possam ser tomadas de maneira absoluta. A primeira delas se dá quando a pessoa tenha deixado expressa, antes da situação que a levou à inconsciência, a vontade de ter a morte antecipada caso sobreviesse tal circunstância ${ }^{20}$.

Uma segunda hipótese estudada pelo autor seria quando a pessoa inconsciente não houvesse manifestado de maneira expressa o seu consentimento. Para enfrentar essa questão, Dworkin propõe a teoria dos melhores interesses ${ }^{21}$ do paciente inconsciente, afirmando que

\footnotetext{
20 Vide Resolução 1995/12 do CFM que trata sobre Testamento Vital, em que o médico fica obrigado a observar e a acolher a vontade do paciente desde que a mesma não contrarie o Direito e nem as orientações da ética médica. "Art. 1o Definir diretivas antecipadas de vontade como o conjunto de desejos, prévia e expressamente manifestados pelo paciente, sobre cuidados e tratamentos que quer, ou não, receber no momento em que estiver incapacitado de expressar, livre e autonomamente, sua vontade."

${ }^{21}$ Dworkin diferencia o interesse experiencial do interesse crítico, afirmando que o primeiro seria o conjunto das atitudes que o sujeito realiza com frequência, com a finalidade de alcançar o prazer imediato, enquanto o segundo, seria representado pelas iniciativas do indivíduo que envolvem juízos críticos, as quais realiza porque crê que elas trazem enobrecimento para a sua existência. Segundo Joseane Cauduro: "A diferença estabelecida entre os interesses experienciais e os críticos ajuda a entender o sentido que cada pessoa dá a sua própria vida. Algumas delas buscam a satisfação material e imediata, outras abrem mão de tudo em busca de um ideal [...] Dworkin acredita que, a partir da compreensão dos interesses acima transcritos, pode-se entender as razões relevantes para se
} 
facilmente seria possível extrair a sua vontade a partir do que informam os seus próximos e, assim, suprir a ausência de expresso consentimento, devendo esses interesses prevalecer sobre o valor intrínseco da vida, à semelhança do que o autor defende para os casos dos pacientes conscientes (CAUDURO, 2007) ${ }^{22}$.

No que concerne a essa primeira possibilidade enfrentada pelo autor, há de se notar coerente a objeção levantada por Silva, no sentido de que não se leva em consideração o fato de que a pessoa possa ter mudado de opinião após a declaração da vontade e antes da superveniência do estado inconsciente, ou tê-la feito sob forte emoção, ou na ausência de sua plena consciência, ou ainda, contra a sua íntima vontade, pensando em evitar um peso e sofrimento para os seus familiares (SILVA, 2011).

Mais especificamente quanto à segunda, é preciso alertar para o risco de se estar - em vez de descobrindo a vontade íntima da pessoa - construindo algo que se assente, sobretudo, na vontade dos seus responsáveis, que podem certamente fazê-lo em tentativa de evitar seu próprio sofrimento, de tirar proveito do patrimônio ou tirar de si o fardo do cuidado com o paciente inconsciente.

Ademais, é lúcido o posicionamento de Silva, ao expressar seu convencimento quanto à indissociabilidade do corpo e da história de uma pessoa, concordando com o pensamento de Robert George, no sentido de que, em todos os casos, está a se tratar de uma vida humana, não de um vegetal (SILVA, 2011). Ademais, questiona-se, de maneira geral, a disposição do valor intrínseco da vida humana, ou, em outros termos, a concepção heterônoma da dignidade humana no caso de antecipação da morte de pessoas inconscientes, embora haja autorizada doutrina que afirma que a concepção autônoma da dignidade seja a predominante na Constituição brasileira ${ }^{23}$.

Contudo, ainda que se admita esse predomínio, algo bastante diversa seria dar-lhe como critério absoluto, o que não é o caso. De todo modo, importa salientar que o processo de

decidir em prosseguir lutando pela vida ou se entregar à morte. [...] A busca por seus verdadeiros valores tem essencial importância, desvendar a forma como ele [o sujeito inconsciente] escolheu guiar sua vida, quais os valores que priorizava em sua caminhada". (CAUDURO, 2007, p.68-70).

22 Diniz e Costa (, [s.d.] p.128) dão a entender que, embora não esteja legalizada no Brasil, esta prática é mais comum do que o que se pensa.

${ }^{23}$ Martel e Barroso são enfáticos no sentido de reconhecer a prevalência da concepção da dignidade como autonomia no ordenamento jurídico brasileiro. Referidos autores apontam ainda críticas à concepção heterônoma da dignidade, haja vista confrontarem-se, no caso envolvendo o tema ora enfrentado, dois de seus pilares de sustentação - a proteção da vida em si versus a proibição de tratamento humano degradante. Contudo, afirmam também de maneira expressa que deve haver o consentimento livre e manifesto do paciente, para que possa haver disponibilidade, excluído, portanto, em tese, a eutanásia em paciente inconsciente - aparentemente ressalvando-se os casos em que este consentimento foi expresso em momento anterior. Afirmam ainda que a principal tarefa no momento em que se vive no Brasil é produzir consenso acerca da ortotanásia. No entanto, como se explicou no item 1 deste artigo, na concepção de Martel, algumas condutas aqui caracterizadas como eutanásia passiva podem ser inseridas como ortotanásia. (MARTEL; BARROSO, ([s.d.]). 
ausculta deve ser o primordial para o aferimento da vontade. Dessa forma, é possível assentir com o entendimento de que, nos casos de antecipação da morte - ainda que em sua modalidade passiva, com a retirada de cuidados básicos, como alimentação, hidratação e higiene - deve haver a prevalência da dignidade enquanto veículo da autonomia da vontade. Isso porque o que parece justificar a noção de heteronomia é exatamente o pluralismo, para que o ser humano possa manifestar as mais diferentes formas de ser, e não de não ser (PESSINI, 2008).

Além disso, interessam as críticas de Silva (2011) aos argumentos favoráveis à possibilidade de eutanásia para os pacientes em estado de inconsciência como corolário da autonomia. Utilizando-se de uma analogia ao pensamento de Habermas acerca da tensão entre autonomia individual e intervenções genéticas na concepção humana, Habermas questiona se a tecnicização da natureza não iria, afinal, resultar em modificações profundas na própria autocompreensão ética da espécie humana, a partir da possibilidade que teriam os pais, por exemplo, de escolher características genéticas e estéticas de seus filhos.

Indaga ainda se o fruto desses experimentos se sentiria, pois, um sujeito ou um objeto? Da mesma maneira, como permitir que uma pessoa tome decisões a respeito do destino de outra, ainda que esta seja considerada inconsciente, pressupondo o que seria de sua vontade? Existe sempre uma grande possibilidade, portanto, de subversão dos interesses críticos individuais. Conclui, assim, pela impossibilidade de se estabelecer "uma relação simétrica entre ‘programado' (produto) e 'programador’”, o que poria, em última instância, em risco a própria autonomia da vontade (SILVA, 2011).

Portanto, é preciso ressaltar que o intuito de todo o exercício da autonomia da vontade, seja do paciente, seja de seus familiares, deve ser sempre no sentido de optar entre as alternativas possíveis para buscar o melhor conforto e suporte, jamais meramente de antecipar o momento do óbito. Com efeito, é interessante observar que a politização em torno desse tema tem perversamente gerado mais debates e menos atenção sobre quais são as maneiras possíveis de se proporcionar, de fato, uma boa morte (SILVA, 2011).

\section{OS DEVERES FUNDAMENTAIS E A PRESERVAÇÃO DA VIDA DOS PACIENTES INCONSCIENTES}

Bobbio (1992, p. 49) afirmou certa vez que: “com uma metáfora usual, pode-se dizer que direito e dever são como o verso e o reverso de uma mesma moeda. Mas qual é o verso e o 
reverso? Depende da posição com que olhamos a moeda". Desse modo, declarou que "a figura deôntica originária é o dever, não o direito"(BOBBIO, 1992, p. 56).

Esclareceu que a concepção dos direitos sobrepostos aos deveres já prevalecia em Roma, mas foi nos séculos XVII e XVIII que surgiu a doutrina dos direitos do homem, a qual tem ganhado cada vez mais espaço desde então, a ponto de o próprio autor ter denominado a época em que viveu de "A era dos direitos". No entanto, com o passar do tempo, especialmente após a reviravolta política e social do segundo pós-guerra, verificou-se o esquecimento dos deveres em geral.

De acordo com Nabais, isso se deu principalmente em razão da preocupação, dominante àquela época, com a instituição "de regimes que se opusessem de uma maneira plenamente eficaz a todas e quaisquer tentativas de regresso ao passado totalitário ou autoritário. Era, pois, necessário exorcizar o passado dominado por deveres, ou melhor, por deveres sem direitos" 24 .

Essa postura se incrustou no imaginário jurídico e cultural (LIPOVETSKY, 2005), de tal modo que, até os dias atuais, o discurso acerca dos deveres fundamentais enquanto categorias necessárias à compreensão do lugar da pessoa humana em face dos direitos fundamentais é considerado por muitos como fora de moda e encontra dificuldade de se inserir no meio político e jurídico (NABAIS, 2002, p. 11). Nabais aponta, inclusive, que os deveres fundamentais, ontologicamente falando, foram objeto "de um pacto de silêncio, de um verdadeiro desprezo" (NABAIS, 2002, p. 12).

Muito embora se tenha feito a opção por essa postura, há que se ressaltar que, no plano fático, isso não altera a necessidade de sua existência, ou seja, os direitos não deixam de ter os seus custos e os seus ônus, nem deixam de requerer abstenções da prática de determinados atos e, às vezes, até mesmo ações específicas voltadas a um determinado sentido.

Percebe-se, portanto, que, no caso ora em estudo, a concepção de deveres fundamentais está radicalmente relacionada à noção de dignidade como heteronomia. Imprescindível é o esclarecimento de que nenhuma espécie de biologização do sofrimento pode implicar em desapego à construção e à valorização da subjetividade, independentemente do estado geral da pessoa. Daí, afirmar-se que o corolário natural da autonomia é a percepção da dignidade no sentido de adensar a singularidade de cada pessoa e em emular cada vez mais e melhor o seu protagonismo, nos âmbitos público e privado.

${ }^{24}$ NABAIS, José Casalta. A face oculta dos direitos fundamentais: os deveres e o custo dos direitos. p.9-30. Revista Direito Mackenzie, ano 3, n.2, 2002, p. 13. 
Desse modo, é preciso reconhecer que os deveres fundamentais merecem o mesmo status conferido aos direitos fundamentais, ou seja, devem ser reconhecidos no plano constitucional como categorias jurídicas autônomas (CANOTILHO, 2003), embora seja possível observar uma relação próxima entre alguns deveres e alguns direitos fundamentais, como é o caso da proteção à vida das pessoas inconscientes.

Ainda quanto à natureza dos deveres fundamentais, é importante fazer uma consideração: ao contrário dos direitos fundamentais, que têm, como visto no item anterior, aplicabilidade imediata, o mesmo não acontece, com algumas poucas exceções ${ }^{25}$, aos deveres fundamentais. No entanto, Canotilho explica que isso não autoriza a denominá-las de normas programáticas; trata-se, na verdade, de dispositivos constitucionais que carecem da mediação do legislador infraconstitucional.

Assim, o direito à autodeterminação é deferido a todos, indistintamente. O exercício da subjetividade é limitado em razão do dever de respeito aos direitos aos outros. Autonomia, assim como a ideia de dignidade não pode, todavia, ser analisada abstratamente, sem a devida contextualização, a dizer, sem os dados identitários que compõem o sujeito, a sua história e a sua concepção de mundo.

\subsection{O conteúdo dos deveres fundamentais de preservação da vida das pessoas inconscientes}

Expostas as noções gerais que envolvem a concepção dos deveres fundamentais, passase, agora, ao detalhamento de alguns comandos essenciais à proteção da vida das pessoas inconscientes.

\subsubsection{Os Deveres do Estado:}

a) Dever de regulamentação

Atualmente, pode-se dizer que há uma insegurança jurídica por parte da comunidade médica no que diz respeito à dispensa de tratamentos fúteis ou extraordinários ao paciente em estado comatoso, tendo em vista que não há uma lei federal para disciplinar o assunto.

O único ato normativo existente até bem pouco era a Resolução n. 1.805/2006 do Conselho Federal de Medicina - CMF, contra a qual o Ministério Público Federal interpôs a Ação Civil Pública n. 2007.34.00.014809-3, com a finalidade de suspendê-lo. Um dos

${ }^{25}$ J. J. Gomes Canotilho (2003)explica que, excepcionalmente, os deveres fundamentais podem ter aplicabilidade imediata. É o caso dos deveres "directamente exigíveis", dos quais ele exemplifica o dever de educação dos filhos. 
fundamentos da ação seria que o CFM não seria competente para tratar da temática, que envolve direito constitucional e que o CFM não poderia regularizar prática prevista como crime ${ }^{26}$. A $14^{\mathrm{a}}$ vara federal do Distrito Federal chegou a conceder liminar favorável ao pleito do MPF, porém, em 6/12/2010, revogou a antecipação de tutela e julgou improcedente o pedido.

Em 2009, no entanto, o CFM publicou a Resoluçāo n. 1931, vulgarmente conhecida como o novo Código de ética médica. Segundo esse documento é vedado ao profissional da medicina o uso de qualquer terapêutica desnecessária ou proibida pela legislação vigente no Brasil. Assegura a liberdade de consciência do médico e veda qualquer tratamento desumano que viole a dignidade do paciente no sentido de enaltecer a autonomia do mesmo, sobretudo a autonomia existencial.

Enfatiza o direito à informação, essência da relação tanto com o paciente quanto com os seus familiares ou os representantes. Veda a abreviação da vida do paciente e o cometimento de crimes, mas elucida a necessidade de observância do estado geral do paciente para evitar qualquer método, tratamento ou diagnóstico fútil, cruel, obstinado ou danoso, mormente aqueles que forem contrários à vontade manifesta do próprio paciente ou de seus representantes.

O novo Código de Ética Médica enalteceu o dever do profissional da medicina de oferecer e assegurar os cuidados paliativos aos pacientes em estado terminal, assegurando a vedação expressa ao prolongamento obstinado da vida mesmo em casos que resultem em transplantação de órgãos e tecidos. Contemplou a regulamentação acerca da importância do prontuário médico e orientou que se trata de documento no qual deve ser registrada a disposição de vontade do paciente ou de seus familiares ou de seus representantes.

Seguindo essa mesma linha de raciocínio, em 2012, o CFM dispôs sobre as diretivas antecipadas de vontade dos pacientes no teor da Resolução n. 1995, intentando bloquear o uso da biotecnologia para prolongar e infligir sofrimento desnecessário aos pacientes em estado terminal, principalmente no caso de existência de autêntica manifestação de vontade antecipadamente expressa.

Importa aclarar que cabe ao profissional da medicina considerar a relevância da antecipação da vontade do paciente no sentido de que sua autonomia seja preservada e que, apenas em casos em que essa vontade não possa ser extraída, nem do próprio paciente, tampouco de seus familiares e ou representantes, deverá se recorrer ao comitê de bioética.

${ }^{26}$ Como se viu no decorrer do item 1 deste artigo, a ortotanásia não é tipificada no Código Penal brasileiro, diferentemente da eutanásia ativa ou passiva. 
Apesar desses esforços empreendidos pelo CFM ainda está evidente o vácuo legislativo no Ordenamento pátrio, sobretudo em razão da falta de apreciação do projeto de codificação penal (PLS 236 de 2012) que tendia a se apropriar dessa problemática para fins de regulamentação.

b) Dever de implementação da Política Nacional de Internação Domiciliar e de fiscalização do adequado fornecimento deste serviço pelos planos de saúde

Em razão da fundamentalidade material e formal do direito à saúde, trata-se de dever fundamental à implantação de politicas públicas nessa área. Daí, nas situações em que o paciente tenha sua saúde gravemente comprometida, porém, que não haja mais necessidade de internamento hospitalar, torna-se de grande importância o serviço de home care ou de internação domiciliar.

Em 2002, a Lei 10.424/2002 estabeleceu no Sistema Único de Saúde - (SUS) a internação domiciliar e o atendimento domiciliar. Em 2006, foi instituída a Política Nacional de Internação Domiciliar. No entanto, o seu alcance ainda está muito aquém das necessidades da população brasileira. Somente em 2011 criou-se, a partir da Portaria 2.029, de 24 de agosto de 2011, a Atenção Domiciliar no âmbito do Sistema Único de Saúde, com diretrizes de atuação, requisitos para cadastro e modalidades de atendimento ${ }^{27}$. Ademais, trata-se de política de adesão, não sendo obrigatória sua adoção, o que se configura verdadeira contradição no que diz respeito à efetivação da dignidade dos pacientes e familiares cuidadores ${ }^{28}$.

Ainda é dever do Estado fiscalizar e garantir o cumprimento da prestação do serviço de internação domiciliar também pelos planos de saúde, que não raro criam dificuldades para os clientes que fazem jus a este tipo de serviço e precisam fazer uso dele ${ }^{29}$.

27 Para melhor compreender a estrutura do programa, conferir a íntegra da Portaria 2.920, disponível em: <http://bvsms.saude.gov.br/bvs/saudelegis/gm/2011/prt2029_24_08_2011.html>. Acesso em: 01 jul. 2012.

${ }^{28}$ REDE pública de saúde oferecerá internação domiciliar. 19 out. 2006. Ministério da Saúde. Disponível em: < http://sna.saude.gov.br/imprimir.cfm?id=3368>. Acesso em: 01 jul. 2012.

${ }^{29}$ De acordo com o Art. 13 da Resolução normativa n. 211, de 11 de janeiro de 2010, da Agência Nacional de Saúde Suplementar, Agência Reguladora de planos de saúde do Brasil: "Caso a operadora ofereça a internação domiciliar em substituição à internação hospitalar, com ou sem previsão contratual, deverá obedecer às exigências previstas nos normativos vigentes da Agência Nacional de Vigilância Sanitária- ANVISA e nas alíneas "c", "d" e "e" do inciso II do artigo 12 da Lei no 9.656, de 1998. Parágrafo único. Nos casos em que a assistência domiciliar não se dê em substituição à internação hospitalar, esta deverá obedecer à previsão contratual ou à negociação entre as partes". O art. 16, VI, garante, também, o fornecimento dos medicamentos para tratamento domiciliar, nos casos previstos pelo art. 13. Disponível em: < http://www.ans.gov.br/index2.php?option=com_legislacao\& view=legislacao\&task=TextoLei\&format=raw\&id=1575>. De acordo com o advogado Luciano Brandão (CONSIDERAÇÕES, 2010), especialista em direito à saúde, a frequente negativa dos planos de saúde em ofertar este tipo de serviço é injustificável, tendo em vista que os custos, relativamente à internação hospitalar, chegam a ser $60 \%$ menores. Para corrigir esta distorção, há farta jurisprudência pátria que reconhece o direito ao internamento domiciliar, quando isto deveria acontecer de pronto. Nesse sentido: Apelação Cível. Seguro de Reembolso de Despesas Médicas e/ou Hospitalares. Atendimento Médico Domiciliar - Home Care. Previsão Contratual. 
c) Ofertar assistência social adequada aos pacientes e aos familiares em regime de internação domiciliar

Além da política de atenção e internação domiciliar, também é fundamental que o Estado cumpra com o dever de assistência social para com os pacientes inconscientes e com seus cuidadores.

A Constituição, em seus artigos 203 e 204, garante a prestação de assistência social, a quem dela necessitar. A Lei Orgânica da Assistência Social - Lei 8.742/1993, em seus artigos 20 e parágrafos, garante um salário mínimo à pessoa com deficiência e ao idoso com mais de 65 anos que comprovem não possuir meios de provimento próprio e de sua família. Para fazer jus a esse benefício, a renda familiar deve ser inferior a um quarto do salário mínimo. Observa-se que se está a falar de uma política importante. Além disso, é justo que se dê ao cuidador condições para uma vida digna, já que é comum que essas pessoas passem a dedicar todo o seu tempo ao enfermo.

Assim, de modo geral, parece justo que o cuidador do paciente inconsciente seja incluído nas políticas assistenciais, sob pena de violação de seus direitos, como: ao lazer, ao trabalho e até ao livre e pleno desenvolvimento da personalidade.

d) Oferecer formação transdisciplinar humanizada aos profissionais de saúde para lidar com as situações de terminalidade da vida

A formação de profissionais para o trabalho com cuidados paliativos em equipes multidisciplinares é fundamental para apoiar o paciente e a família. Contudo, o que se verifica, em regra, é um despreparo dos profissionais para lidar com as situações de terminalidade da vida, que são de altíssima frequência no cotidiano dos profissionais da saúde ${ }^{30}$.

Nesse sentido, é fundamental que a formação dos profissionais de saúde não se dê por sua única e exclusiva iniciativa (PEREIRA; LOPES, 2007). É preciso que existam programas contínuos de educação e de preparo dos profissionais para lidar com tais situações. É importante

\footnotetext{
Aplicação das Normas do CDC. Exclusão do fornecimento de Medicamentos para o tratamento prevista na Lei $\mathrm{N}^{\mathrm{o}}$ 9.656/98. Hipótese em que o autor apresenta grave estado de saúde, necessitando de atendimento e acompanhamento médico em seu domicílio, pois não se trata de caso de internação hospitalar. Situação em que os custos para a seguradora são muito inferiores que o tratamento hospitalar. Exclusão contratual para atendimento médico domiciliar que deve ser analisada, no caso dos autos, de acordo com as disposições do Código de Defesa do Consumidor. Sentença mantida. APELAÇÃO DESPROVIDA. (TJRS - $6^{\mathrm{a}}$ Câmara Cível - Apelação Cível - N 70011308954 - Rel. Dr. José Conrado de Souza Júnior - j. 27.04.2006.

${ }^{30}$ De acordo com a Dra. Dalva Yukie Matsumoto (CUIDADOS, [s.d.]), coordenadora do Programa de Cuidados Paliativos do Hospital do Servidor Público Municipal de São Paulo, na prática, os maiores problemas enfrentados por quem trabalha com cuidados paliativos são "o pouco treinamento que a grande maioria dos médicos especialistas tem para tratar a dor de forma adequada e abordar os outros sintomas desagradáveis que se instalam na fase avançada da doença crônica, e a falta de preparo para ajudar nas questões que envolvem a família, especialmente as de ordem emocional e espiritual".
} 
ressaltar que é indispensável o acompanhamento por equipes transdisciplinares que apoiem tanto o familiar quanto o cuidador, até mesmo para ajudar no discernimento quanto às melhores escolhas para o paciente.

\subsubsection{Deveres dos profissionais de saúde}

Além do cuidado adequado a ser dispensado ao paciente e aos seus familiares, é imprescindível que se assegure a plena informação sobre a situação do paciente. O profissional de saúde tem o dever permanente de orientação, de acompanhamento e de apoio, dentro da competência e das funções de cada área. Com efeito, os deveres se circunscrevem a cada uma das profissões da área da saúde naquilo que os distinguem em sua especificidade e, via de regra, estão dispostos nas regulamentações dos conselhos, mas seguem o padrão constitucionalmente disposto que exige a integralidade da tutela à pessoa humana.

\subsubsection{Dever de cuidado pela família}

Por fim, apresenta-se o dever de cuidado pela família, expressamente previsto em âmbito constitucional, nos moldes do caput do artigo 227.

A família é, de fato, a instituição que deve prioritariamente acompanhar a pessoa desde os primeiros dias de vida e permanecer prestando assistência, carinho, atenção e cuidado durante o seu desenvolvimento até o ocaso. Em geral, tem-se a vida intrafamiliar como modelo para o processo de amadurecimento da pessoa humana que se perfaz no intervalo desde a tenra infância até a velhice, etapa que vai traduzindo-se pela sistemática falência dos sentidos. Embora não seja tão comum, pode acontecer de o estado de inconsciência sobrevir ainda na juventude.

Em momentos difíceis, independentemente da idade do sujeito, a família tem o dever de compartilhá-los e de não abandonar seus membros. É o que se desprende dos artigos 229 e 230 da Constituição. Cumpre ressaltar que a velhice é, pois, uma das fases de maior vulnerabilidade do indivíduo, que, muitas vezes, já não pode mais executar tarefas básicas com a mesma habilidade de outrora. Ademais, no curso do processo de envelhecimento, surgem grande parte das enfermidades que possivelmente serão as causas do seu óbito, implicando, necessariamente, um aumento gradual de atenção e do dever de acompanhamento por parte dos familiares. 
Para bem cumprir os seus deveres, a família precisa se preparar para esse momento, para dar todo o suporte necessário para os momentos que antecedem a morte, sobretudo apoiando e respeitando a esfera da autonomia existencial do indivíduo.

\section{MIRADAS FINAIS}

Extremamente complexo e controvertido, esse tema não admite consensos forjados nem apreciações aligeiradas em seus elementos mais simples: nem quanto ao conceito de vida, nem de morte, nem de dignidade, nem de eutanásia, quem dirá da delimitação e da plena compreensão sobre os estados de inconsciência.

Com efeito, a atual necessidade de reestruturação do regime das incapacidades no Brasil nos aponta para a urgência de uma superação teórica e prática que, a despeito da patrimonialidade inerente ao fenômeno jurídico, deve ser valorizado o aspecto existencial e, nessa medida, ampliadas as formas de modos de expressão de vontade por meio de distintos meios, graus e modos de discernimento.

Lembrando que a observância da concepção de autonomia deve fugir ao padrão estreito da racionalidade moderna e não pode ser reduzida a uma ideia preconcebida de normalidade e de competência para tomada de decisões. Faz-se necessária uma expansão de novos modos de apreensão da manifestação da vontade que comporte, inclusive os atuais desafios oportunizados pela biotecnologia, à ideia de discernimento.

Quanto a isso, cumpre destacar a relevância da regulamentação advinda a partir da vigência da Lei 13.146/2013, vulgarmente conhecido como Estatuto da Pessoa com deficiência, ratificado na forma do $\S 3^{\circ}$, art. $5^{\circ}$ da $\mathrm{CF} / 88$ e tendo como base o teor da Convenção de Nova York e seu protocolo facultativo, sobretudo no que tange à reinterpretação do instituto do mandado.

Essas constatações de vácuo de legislação específica não devem ser um desestímulo à discussão, uma vez que o processo de morte é inevitável e em todas as suas circunstâncias, são sempre legítimas indagações acerca dela. Enfim, enquanto persiste a mortalidade, resulta para o Homem mais do que o direito, o dever de refletir sobre todas as questões existenciais que esboçam e contornam a condição humana. Persiste, pois, a indagação em como seria possível ser melhor e até mais humano em todas as etapas da vida.

Enquanto isso, persiste igualmente a necessidade de encontrar entendimentos que fundamentem as decisões mais adequadas, de acordo com o tempo e a tecnologia disponível, 
para possibilitar conforto, o devido desenvolvimento da personalidade e a dignidade da pessoa no momento da morte.

As dúvidas quanto à concretização desse patamar normativo, no entanto, ecoam em profusão. Na dúvida, acredita-se, deve-se decidir pela vida, por deixá-la seguir seu curso sem prolongamento de sofrimentos artificiais. Aqui não se inserem os insumos básicos da sobrevida, como higiene, alimentação e hidratação. Disso decorrem deveres fundamentais a serem observados pelo Estado, pelos profissionais da saúde e pelos familiares, especialmente quando se trata de paciente que já se encontra em um estágio em que tanto a autonomia quanto a capacidade de expressão se encontram muito prejudicadas.

Em situações dessa ordem, incontestavelmente, verifica-se que a tutela deve ser proporcional à vulnerabilidade no sentido de implicar em um grau de proteção que possa assegurar ao paciente o maior grau de conforto em razão da menor quantidade de sofrimento. Lembrando que qualquer restrição à autonomia só é legitimada por circunstâncias que efetivamente impliquem em favorecimento real para a condição do paciente.

Intenta-se ainda enfatizar a importância da preparação do Estado para assumir seus deveres em uma teia forjada pela responsabilidade e pela solidariedade de todos os atores envolvidos, a dizer, a família, os responsáveis e os profissionais da área da saúde. Nessa composição solidária, resta evidente a necessidade da busca pela valorização e pela preservação da autonomia existencial do paciente em todas as fases de sua vida, notadamente, em fase terminal.

Cabe ao paciente deliberar, discernir, avaliar, ponderar, decidir da maneira mais autônoma possível tendo como base a informação precisa, autêntica, suficiente e clara tanto acerca do seu diagnóstico quanto do seu prognóstico. Observa-se que o dever de informação deve ser assegurado desde a oralidade própria das consultas, passando pelo manejo dos prontuários, até a disponibilização de dados em pesquisas ou na internet.

Nesse contexto, cabe ao Estado preservar essa zona de liberdade e de livre desenvolvimento da personalidade dentro dos contornos da dignidade e da autonomia existencial que atualmente são oportunizados com base no ordenamento jurídico brasileiro, na seara constitucional e na infraconstitucional. Somente na inexistência da total condição de expressão da vontade por parte do paciente, de seus familiares e ou de seus representantes, em face do vácuo legislativo que persiste no Brasil no que tange à incipiente regulamentação da eutanásia, da ortotanásia e da distanásia, deve-se buscar na deliberação colegiada do comitê de bioética de cada das instituições de saúde a saída legítima para orientar os atos dos profissionais. 
Por fim, cumpre reconhecer que o fio que deve tecer a urdidura da vida é o mesmo que deve arrematar o processo que culmina na morte, a dizer, que a sua composição deve ser fundamentalmente pautada no protagonismo pessoal que visa indistintamente à integralidade da pessoa humana em todos os seus estágios, etapas e vivências.

\section{REFERÊNCIAS}

ANJOS, Augusto dos. Budismo Moderno. Eu e outras poesias. 42. ed. Rio de Janeiro: Civilização Brasileira, 1998. Versão digitalizada. Disponível em: < http://www.labtecgc.udesc.br:8081/pgbd/bitstream/123456789/460/1/Eu\%20e\%20ou tras\%20poesias\%20-\%20Augusto\%20dos\%20Anjos.pdf>. Acesso em: 01 jul. 2012.

BAIGES, Victor Méndez. Sobre morir - eutanásias, derechos, razones. Madrid: Trotta, 2002.

BOBBIO, Norberto. A era dos direitos. 13 tir. Rio de Janeiro: Campus, 1992.

CANOTILHO, José Joaquim Gomes. Direito constitucional e teoria da constituição. 7. ed. Coimbra: Almedina, 2003.

CAUDURO, Joseane. O conceito de eutanásia em Dworkin. Dissertação (Mestrado em Direito) Universidade de Caxias do Sul, Caxias do Sul, 2007.

CONSIDERAÇÕES sobre a cobertura do sistema Home Care pelos planos de saúde. 05 abr. 2010. Direito e Saúde. Disponível em: http://direitoesaude.wordpress.com/2010/04/05/consideracoes-sobre-a-cobertura-do-sistema-dehome-care-pelos-planos-de-saude/>. Acesso em: 01 jul. 2012.

CUIDADOS paliativos. Dráuzio Varella. Disponível em: < http://drauziovarella.com.br/ envelhecimento/cuidados-paliativos/>. Acesso em: 01 jul. 2012.

DINIZ, Débora; COSTA, Sérgio. Morrer com dignidade: um direito fundamental. IPEA, [s.d.] p.128. Disponível em: < www.ipea.gov.br/sites/000/2/livros/.../Arq_10_Cap_04.pdf>. Acesso em: 25 jun. 2012.

FLÁVIA: 20 anos, metade dos quais em coma. Flávia, vivendo em coma. 16 dez 2007. Disponível em: <http://flaviavivendoemcoma.blogspot.com.br/2007/12/flavia-20-anos-metadedos-quais-em-coma.html>. Acesso em: 20 jun. 2012.

LIPOVETSKY, Gilles. A sociedade pós-moralista: o crepúsculo do dever e a ética indolor dos novos tempos democráticos. Barueri: Manole, 2005.

MANTENDO a dignidade de Flávia. 22 abr. 2012. Flávia, vivendo em coma. Disponível em: < http://flaviavivendoemcoma.blogspot.com.br/2012/04/mantendo-dignidade-de-flavia.html>. Acesso em: 01 jul. 2012. 
MORAES, Vinícius. Soneto de Fidelidade. Livro de sonetos. Rio de Janeiro: Portugal, 1957. Disponível em< http://www.viniciusdemoraes.com.br/site/article.php3?id_article $=111>$. Acesso em: 20. Mar. 2012.

MARTEL, Letícia de Campos Velho. Direitos fundamentais indisponíveis - os limites e os padrões do consentimento para a autolimitação do direito fundamental à vida. Tese (Doutorado em Direito). Universidade do Estado do Rio de Janeiro, 2010, p. 340. Disponível em: <http://works.bepress.com/leticia_martel/5>. Acesso em: 25 jun. 2012.

MARTEL, Letícia de Campos Velho; BARROSO, Luis Roberto. A morte como ela é: dignidade e autonomia no final da vida, [s.d.], p. 12. Associação Mineira do Ministério Público. Disponível em: <http://www.ammp.org.br/inst/artigo/Artigo-6.pdf>. Acesso em: 25 jun. 2012.

NABAIS, José Casalta. A face oculta dos direitos fundamentais: os deveres e o custo dos direitos. p.9-30. Revista Direito Mackenzie, ano 3, n.2, 2002.

NASCIMENTO, Milton; BRANDT, Fernando. Encontros e Despedidas. Intérprete: Milton Nascimento. In: MILTON NASCIMENTO. Travessia - o melhor de Milton Nascimento. Rio de Janeiro: Universal, 1999, faixa 3.

NOVAIS, Jorge Reis. A Dignidade da Pessoa Humana. Vol I- Dignidade e Direitos Fundamentais. Coimbra: Almedina, 2015.

PEREIRA, Lílian Lopes; DIAS, Ana Cristina Garcia. O familiar cuidador do paciente terminal: o processo de despedida no contexto hospitalar. Psico - Revista de Psicologia da Pontifícia Universidade Católica do Rio Grande do Sul, Porto Alegre, v. 38, n. 1, p.55-65, jan-abr.2007.

PESSINI, Leo. Morte, solução de vida? Uma leitura bioética do filme Mar Adentro. Revista Bioética, vol. 16, n. 1, p. 51-60, 2008, p. 55. Disponível em: <http://revistabioetica.cfm.org.br/>. Acesso em: 20 mar. 2012.

PONTES, Felipe. Depoimentos de brasileiros que se inscreveram na clínica especializada em morte. Revista Época. 23 jun. 2012. Disponível em: <http://revistaepoca.globo.com/vida/noticia/2012/06/depoimentos-de-brasileiros-que-seinscreveram-na-clinica-especializada-em-morte.html>. Acesso em: 23 jun. 2012.

SARAMAGO, José. As intermitências da morte. São Paulo: Companhia das Letras, 2005. SILVA, Mário Tavares da. Eutanásia: alguns aspectos morais. Lisboa: AAFDL, 2011.

SIQUEIRA-BATISTA, Rodrigo; SCHRAMM, Fermin Roland. Eutanásia: pelas veredas da morte e da autonomia. Revista Ciência e Saúde Coletiva, vol. 9, n. 1, p.31-41, 2004. Disponível em: <http://www.scielo.org.br>. Acesso em: 21 mar. 2012.

REDE pública de saúde oferecerá internação domiciliar. 19 out. 2006. Ministério da Saúde. Disponível em: < http://sna.saude.gov.br/imprimir.cfm?id=3368>. Acesso em: 01 jul. 2012.

VILLAS-BÔAS, Maria Elisa. A ortotanásia e o Direito Penal brasileiro. Revista Bioética, vol. 16, n. 1, p.61-83, 2008. Disponível em: <http://revistabioetica.cfm.org.br/>. Acesso em: 21 mar. 2012. 